\title{
Comparison of ET estimations by the three-temperature model, SEBAL model and eddy covariance observations
}

\author{
Xinyao Zhou ${ }^{a}$, Shaojie Bi ${ }^{a}$, Yonghui Yang ${ }^{\mathrm{a}, *}$, Fei Tian ${ }^{\mathrm{b}}$, Dandan Ren ${ }^{\mathrm{a}}$ \\ ${ }^{a}$ Key Laboratory of Agricultural Water Resources, Key Laboratory of Agricultural Water Saving, Center for Agricultural Resources Research, Institute of Genetics and \\ Developmental Biology, Chinese Academy of Sciences, 286 Huaizhong Road, Shijiazhuang 050021, China \\ b State Key Laboratory of Urban and Regional Ecology, Research Center for Eco-Environmental Sciences, Chinese Academy of Sciences, 18 Shuangqing Road, Haidian District, \\ Beijing 100085, China
}

\section{A R T I C L E I N F O}

\section{Article history:}

Received 22 September 2013

Received in revised form 27 May 2014

Accepted 2 August 2014

Available online 10 August 2014

This manuscript was handled by

Konstantine P. Georgakakos, Editor-in-Chief,

with the assistance of Venkat Lakshmi,

Associate Editor

\section{Keywords:}

3T model

SEBAL model

Eddy covariance

Evapotranspiration

Taklamakan desert oasis

\begin{abstract}
S U M M A R Y
The three-temperature (3T) model is a simple model which estimates plant transpiration from only temperature data. In-situ field experimental results have shown that $3 \mathrm{~T}$ is a reliable evapotranspiration (ET) estimation model. Despite encouraging results from recent efforts extending the 3T model to remote sensing applications, literature shows limited comparisons of the 3T model with other remote sensing driven ET models. This research used ET obtained from eddy covariance to evaluate the 3T model and in turn compared the model-simulated ET with that of the more traditional SEBAL (Surface Energy Balance Algorithm for Land) model. A field experiment was conducted in the cotton fields of Taklamakan desert oasis in Xinjiang, Northwest China. Radiation and surface temperature were obtained from hyperspectral and thermal infrared images for clear days in 2013. The images covered the time period of 0900$1800 \mathrm{~h}$ at four different phenological stages of cotton. Meteorological data were automatically recorded in a station located at the center of the cotton field. Results showed that the 3T model accurately captured daily and seasonal variations in ET. As low dry soil surface temperatures induced significant errors in the 3T model, it was unsuitable for estimating ET in the early morning and late afternoon periods. The modelsimulated ET was relatively more accurate for squaring, bolling and boll-opening stages than for seedling stage of cotton during when ET was generally low. Wind speed was apparently not a limiting factor of ET in the 3T model. This was attributed to the fact that surface temperature, a vital input of the model, indirectly accounted for the effect of wind speed on ET. Although the 3T model slightly overestimated ET compared with SEBAL and eddy covariance, it was generally reliable for estimating daytime ET during 0900-1600 h.
\end{abstract}

(c) 2014 Elsevier B.V. All rights reserved.

\section{Introduction}

Evapotranspiration (ET) is a key component of terrestrial energy and water balance (Bastiaanssen, 2000; Zwart and Bastiaanssen, 2004; Thoreson et al., 2009). Accurate estimation of ET is important for efficient water resources planning and management (Cleugh et al., 2007). Classical methods for measuring/estimating ET are only available at the field scale - e.g., the Bowen ratio, eddy covariance, weighing lysimeter (Courault et al., 2005). Recently though, remote sensing models have quickly developed into widely used tools for estimating ET at large spatial scales (Kite and Droogers, 2000). Estimation of regional ET using remote sensing models could be used in regional management of water and land resources (Dodds et al., 2005; Meyer, 1999; Ma et al., 2011; Moiwo et al., 2011).

\footnotetext{
* Corresponding author.

E-mail address: yonghui.yang@sjziasm.ac.cn (Y. Yang).
}

Traditional remote sensing models such as the Surface Energy Balance Algorithm for Land (SEBAL, Bastiaanssen et al., 1998a,b), Mapping ET at high Resolution with Internalized Calibration (METRIC, Allen et al., 2007), the Surface Energy Balance System (SEBS, Su, 2002), the Two-Source Energy Balance (TSEB, Norman et al., 1995) and the Atmosphere-Land Exchange Inverse (ALEXI, Anderson et al., 1997) estimate ET using physical-based energy balance approaches. The challenges of physical-based models include complex algorithms (e.g., aerodynamic resistance and surface resistance algorithms) which require several parameters (Kalma, 1989; Liu et al., 2006; Zhang et al., 2010). Another issue with such models relates to the use of meteorological data in estimating ET at the $200 \mathrm{~m}$ reference height for wind speed (Bastiaanssen et al., 1998a), which is only practical for small areas (Zhang et al., 2011).

Thus research continues to explore new remote sensing models that are driven by simple algorithms, including the Triangle-Based 
Method (TBM, Carlson, 2007), Gross Primary Productivity (GPP, Yang et al., 2013) and the three-temperature model (3T model, Qiu et al., 1996a,b). Amongst the models, the 3T model is driven by in-situ temperature data. At-site growth chamber, greenhouse and open-field experiments have shown that although simple, the 3T model accurately estimates transpiration using limited field observations/parameters (Qiu et al., 1999, 2000, 2002, 2003, 2006). In the $3 \mathrm{~T}$ model, resistance is avoided by using imitation leaf (leaf without transpiration) during the estimation of transpiration. The parameters required for this processes include sunlit leaf (canopy) temperature, imitation leaf temperature, air temperature, plant coverage and solar radiation. Results from grain sorghum field experiments show that the imitation leaf method estimation of daily transpiration is highly accurate (Qiu et al., 1996a).

The imitation leaf method is extended for estimating soil evaporation by accounting for dry soil surface temperature (Qiu et al., 1998). The necessary input variables are temperature (air temperature, drying soil surface temperature and dry soil surface temperature), net radiation and soil heat flux. The first experiment of this nature was conducted in a 1 ha coarse grain sand field in Japan using a weighing lysimeter. Using temperature data from infrared thermometers, the mean absolute error between measured and estimated evaporation was $0.15 \mathrm{~mm} /$ day and with a regression coefficient $\left(R^{2}\right)$ of 0.94 (Qiu et al., 1998).

Because all the parameters are easily obtained from remote sensing images, the 3T model has been extended to regional scale after success verifications with at-site data (Xiong and Qiu, 2011). The revision proposed an ET estimation algorithm for mixed landscapes by redefining reference soil and canopy. The revised 3T model was validated for a semiarid grassland in the Taibus Banner of Inner Mongolia and the Jinghe River Basin of the Loess Plateau, China. For both areas, the Landsat Thematic Mapper (TM) and Enhanced Landsat Thematic Mapper Plus (ETM+) images were used. The Bowen ratio energy balance method (BREBM) and the residual method of the energy balance equation (RMEBE) were used to validate the performance of the revised $3 \mathrm{~T}$ model. Results showed that the mean absolute error (MAE) of daily ET for BREBM and the revised $3 \mathrm{~T}$ model was $0.23 \mathrm{~mm} / \mathrm{day}$, and that for RMEBE and the revised 3T model was $0.07 \mathrm{~mm} /$ day (Xiong and Qiu, 2011).

Using the 3T model and Moderate Resolution Imaging Spectroradiometer (MODIS) satellite data [validated by evaporator pan (E601) data] to estimate daily ET for the Heihe River Basin, Luo et al. (2012) noted a MAE in the range of $0.05-1.7 \mathrm{~mm} / \mathrm{d}$. Also using the 3T model and MODIS products to estimate annual ET in the Heihe River Basin for the period 2001-2009, Tian et al. (2013) noted an annual difference in ET between the $3 \mathrm{~T}$ model and field measured values of 5-72 mm and MAE of $25.5 \mathrm{~mm}$ (Tian et al., 2013).

Although the 3T model has been verified at regional scale, accuracy comparisons with physically-based ET models remain scarce. Also SEBAL is a classical, physically-based remote sensing model with a wide application under different environmental conditions (Allen et al., 2002; Hemakumara et al., 2003; Bastiaanssen and Chandrapala, 2003; Mohamed et al., 2004; Bastiaanssen et al., 2005). Thus the SEBAL model was used in this study to evaluate the 3T model after verification with measured field fluxes.

\section{Model descriptions}

\subsection{Model similarities}

The SEBAL and 3T models are described in detailed by Bastiaanssen et al. (1998a), Qiu et al. (1996a, b), respectively. Thus the highlight here focuses on the main similarities between the models. Both models use energy balance equation to estimate instantaneous surface flux as (Qiu et al., 1996a):
$L E=R_{n}-G-H$

where $L E$ is latent heat flux; $R_{n}$ is net radiation; $G$ is soil heat flux; and $H$ is sensible heat flux. $H$ is estimated using aerodynamic resistance as:

$H=\frac{\rho_{a} C_{p} d T}{r_{a h}}$

where $\rho_{a}$ is air density; $C_{p}$ is specific heat of air; $r_{a h}$ is bulk aerodynamic resistance to heat transport; and $d T$ is difference between surface $\left(T_{s}\right)$ and air $\left(T_{a}\right)$ temperature.

\subsection{Model differences}

The main difference between the SEBAL and 3T models is in the estimation process of aerodynamic resistance $\left(r_{a h}\right)$. In SEBAL, $r_{a h}$ is estimated by Monin-Obuknov similarity hypothesis and complex iterations and recursions (Bastiaanssen et al., 1998a). Because the buoyancy effect on momentum flux is negligible during the first approximation of $r_{a h}$, it yields erroneous estimate of local scale friction velocity $\left(u_{*}\right)$. However, using $u_{*}$ values obtained in the second iterative loop produces an improved second estimate of $u_{*}$. Generally, a total of 5 iterations are usually sufficient to obtain a satisfactory approximation of $\boldsymbol{u}_{*}$ (Bastiaanssen, 2000).

Then in the 3T model, $r_{a h}$ is calculated from temperature and radiation. For this process, assume a small reference surface for dry soil where atmosphere conditions around the reference surface are fairly stable with a non-negligible amount of water in the dry soil and $L E$. Under the given condition, $r_{a h}$ is estimated as (Qiu et al., 1996b):

$r_{a h}=\frac{\rho_{a} C_{p}\left(T_{s d}-T_{a}\right)}{R_{n d}-G_{d}}$

where $T_{s d}, R_{n d}$ and $G_{d}$ are respectively soil temperature, net radiation and soil heat flux of reference dry soil. Then soil evaporation is estimated by combining Eqs. 1-3 as:

$L E_{s}=R_{n, s m}-G-\left(R_{n d}-G_{d}\right) \frac{T_{s}-T_{a}}{T_{s d}-T_{a}}$

where $R_{n, s m}$ is soil net radiation.

Also using a similar method for imitation canopy (canopy without transpiration), $r_{a h}$ is estimated as:

$r_{a h}=\frac{\rho_{a} C_{p}\left(T_{c p}-T_{a}\right)}{R_{n, c p}}$

where $T_{c p}$ and $R_{n, c p}$ are respectively the temperature and net radiation of imitation canopy. Also vegetation transpiration is estimated by combining Eqs. (1), (2) and (5) as:

$L E_{c}=R_{n, c m}-R_{n, c p} \frac{T_{c}-T_{a}}{T_{c p}-T_{a}}$

where $T_{c}$ and $R_{n, c m}$ are respectively the temperature and net radiation of the canopy.

For pixels with mixed soil and vegetation, fractional vegetation cover $(f)$ estimation method (Carlson et al., 1995) is adopted:

$L E=(1-f) L E_{s}+f L E_{c}$

In this study, dry soil column is treated as the dry pixel in calculating for both transpiration and evaporation. This is because imitation leaf temperature is hard to obtain when the models are applied at regional scale. 


\section{Materials and methods}

\subsection{Experimental site}

The study was conducted at the Soil and Water Conservation Monitoring Station in Alaer City, Xinjiang Province. The station is located at latitude $40^{\circ} 37^{\prime} 09^{\prime \prime} \mathrm{N}$ and longitude of $81^{\circ} 11^{\prime} 54^{\prime \prime} \mathrm{E}$, and at an altitude of $1100 \mathrm{~m}$ in the oasis near the northern edge of Taklamakan desert; hereafter referred to as the Taklamakan desert oasis. Annual mean temperature in the region is $10^{\circ} \mathrm{C}$, with hot summers and cold winters. The mean annual precipitation is $52 \mathrm{~mm}$, which is among the driest regions in China. Cotton is the main cultivated crop in the region and glacier melt flow into Akesu River is the main sources of irrigation water in the desert oasis (see Fig. 1).

\subsection{Field measurements}

\subsubsection{Remote sensing data}

The plate on the left in Fig. 2 depicts the hyperspectral imagery taken by Hyperspec VNIR C-Series Imaging Spectrometer (Headwall Co., Ltd.). The spectrometer a wavelength range of $400-1000 \mathrm{~nm}$ and wavelength interval of $3 \mathrm{~nm}$ and the image resolution is less than $0.6 \mathrm{~cm}$. The hyperspectral imageries were analyzed in Image 9 software.

Then the plate on the right in Fig. 2 shows the thermal infrared picture taken by R300 camera (NEC Co., Ltd.). Temperature precision of the camera is $0.05^{\circ} \mathrm{C}$ and the image resolution is less than $0.5 \mathrm{~cm}$. The thermal infrared pictures were recorded, transformed and analyzed in NS9500PRO software.

A drum of dry soil, buried in the cotton field, served as the reference 'dry pixel'. The surface of the dry soil was uncovered and was at the same level with the surrounding soil surface. The drum, consisting of adiabatic plastic wall and aluminum base, was $45 \mathrm{~cm}$ in height, $20 \mathrm{~cm}$ in diameter and $0.5 \mathrm{~cm}$ in wall width. Because of the adiabatic wall separator, energy exchange between the reference dry soil and the surrounding environment was only through the base. Also a drum of saturated soil, sunk into the soil, served as the reference 'wet pixel'. The wet pixel drum was $21 \mathrm{~cm}$ in height, $20 \mathrm{~cm}$ in diameter and $0.8 \mathrm{~cm}$ in wall width. Like the dry pixel drum, the wet pixel drum wall was made of insulating plastic to prevent heat flow through the walls.

Images of the four investigated cotton growth stages were shot every hour from 0900 to $1800 \mathrm{~h}$ on cloud-free days in 2013 (Table 1).

\subsubsection{Eddy covariance and meteorological measurements}

The LI-7500 Eddy covariance system (LI-COR Co., Ltd.) was set up to directly monitor ET in the cotton field. Meteorological data, including wind speed and air temperature, were automatically recorded at meteorological stations (Campbell Co., Ltd.) in the cotton field and in the nearby weather station at heights of $2 \mathrm{~m}$ and $10 \mathrm{~m}$, respectively. Direct shortwave and longwave radiations were measured along with reflected shortwave and longwave radiations every $2 \mathrm{~h}$ using a 4-thermopile net radiometer (Jinzhou Scientific Ltd., China). Two of the thermopiles faced upwards to measure incident shortwave and longwave radiation and the other two faced downwards to measure reflected shortwave and emitted longwave radiation. The measured radiation data were used to calibrate the model-estimated net radiation.

\subsection{SEBAL and $3 T$ model parameter processing}

The relevant input parameters of the SEBAL and 3T models are list in Table 2. As no algorithm was used for resistance, the number of parameters of the 3T model was far less than that of the SEBAL model.

The parameters in Table 2 are defined in the preceding equations. Among the parameters, albedo $(\alpha)$ and NDVI were obtained directly from remote sensing inputs. Albedo was calculated after Yu et al. (2011) as:

$$
\alpha=\left(\begin{array}{c}
0.137 \alpha 1+0.071 \alpha 2+0.142 \alpha 3+0.128 \alpha 4+ \\
0.099 \alpha 8+0.081 \alpha 9+0.082 \alpha 10+0.080 \alpha 11+ \\
0.037 \alpha 14+0.043 \alpha 15+0.039 \alpha 17+0.059 \alpha 19
\end{array}\right)
$$

where $\alpha$ is reflectance of respective bands denoted by numerical numbers in Table 2. Then NDVI was calculated after Crippen (1990) as:

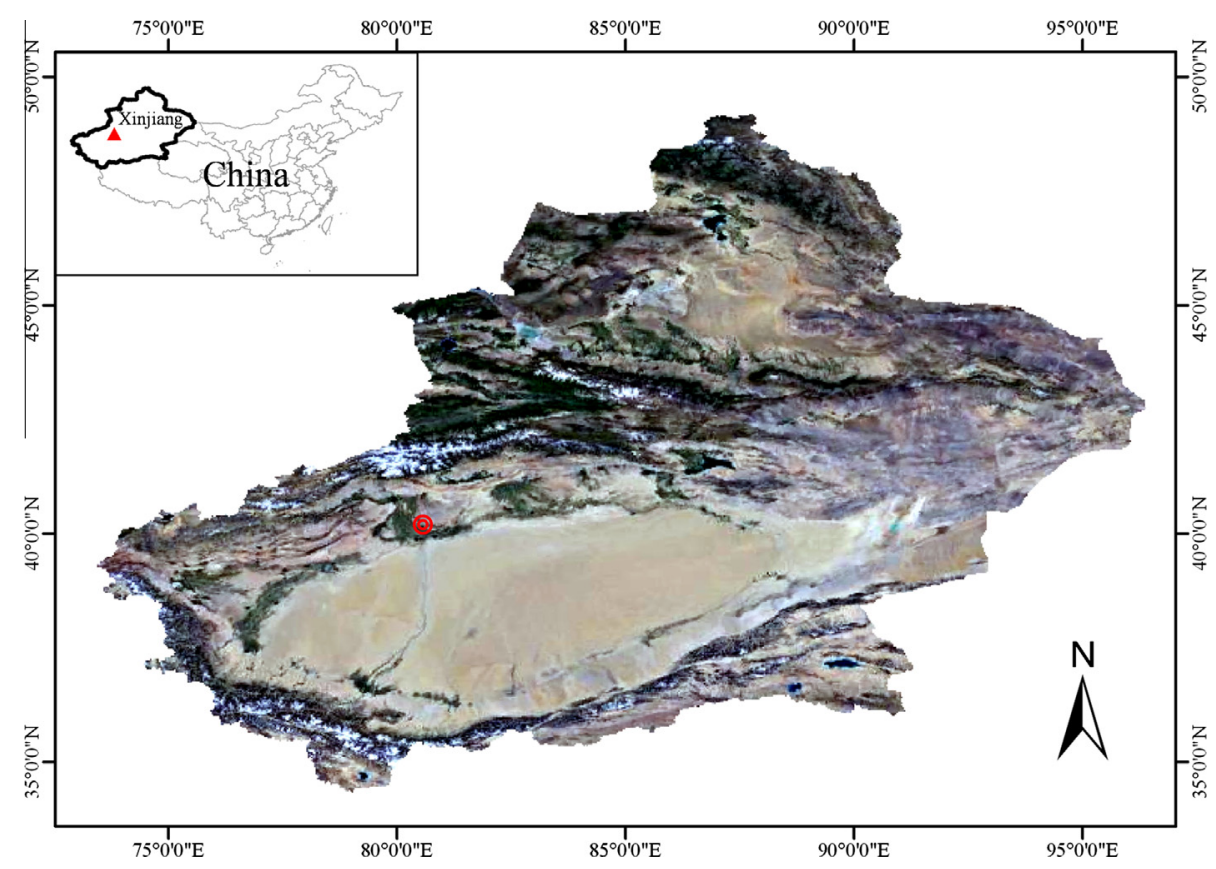

Fig. 1. A map depicting the location of Taklamakan desert oasis (study site) in Xinjiang Province, China. 


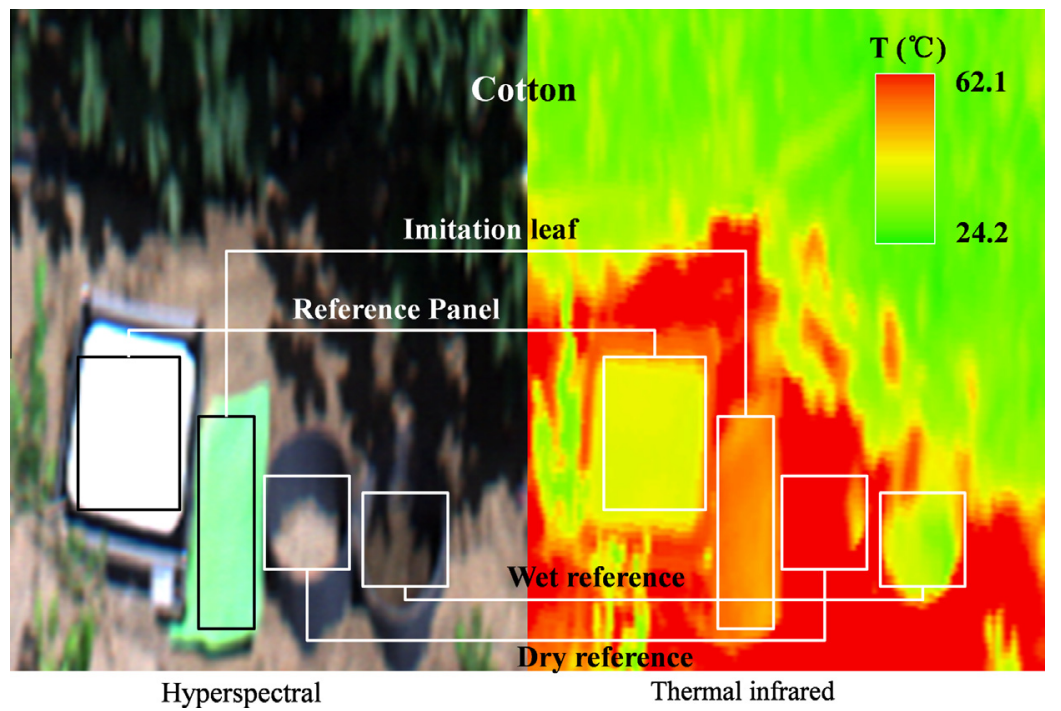

Fig. 2. Hyperspectral and thermal infrared imageries of cotton fields in Taklamakan desert oasis taken at $1200 \mathrm{~h}$ midday on the 30 th of July 2013.

Table 1

Meteorological data and phenological variables during image shooting in cotton fields in Taklamakan desert oasis.

\begin{tabular}{llllll}
\hline Date & $\begin{array}{l}\text { ET from eddy } \\
\text { covariance } \\
(\mathrm{mm} / \text { day })\end{array}$ & $\begin{array}{l}\text { Mean } \\
\text { temperature } \\
\left({ }^{\circ} \mathrm{C}\right)\end{array}$ & $\begin{array}{l}\text { Mean wind } \\
\text { speed }(\mathrm{m} / \mathrm{s})\end{array}$ & NDVI & Stage \\
\hline $2013 / 06 / 01$ & 2.17 & 32.36 & 2.38 & 0.29 & Seedling \\
$2013 / 07 / 05$ & 5.80 & 32.00 & 4.16 & 0.80 & Squaring \\
$2013 / 07 / 30$ & 6.28 & 34.30 & 2.00 & 0.77 & Bolling \\
$2013 / 08 / 31$ & 5.49 & 29.10 & 3.40 & 0.70 & Boll opening \\
\hline
\end{tabular}

$N D V I=\frac{\rho 2-\rho 1}{\rho 2+\rho 1}$

where $\rho 1$ and $\rho 2$ are respectively the reflectances of bands 1 and 2 of red and near infrared red light.

\subsection{Data analysis}

The coefficient of determination $\left(R^{2}\right)$, the Root Mean Square Error (RMSE) and the Normalized Root Mean Square Error (NRMSE) were used as measure of accuracy by comparing the estimated and measured datasets. The equations for $R^{2}$, RMSE and NRMSE are as follows:

$R^{2}=\left(\frac{\sum_{i=1}^{n}\left(E T_{R S, i}-\overline{E T_{R S}}\right)\left(E T_{E C, i}-\overline{E T_{E C}}\right)}{\sqrt{\sum_{i=1}^{n}\left(E T_{R S, i}-\overline{E T_{R S}}\right)^{2} \sum_{i=1}^{n}\left(E T_{E C, i}-\overline{E T_{E C}}\right)^{2}}}\right)^{2}$
$R M S E=\sqrt{\frac{\sum_{i=1}^{n}\left(E T_{R S, i}-E T_{E C, i}\right)^{2}}{n}}$

$N R M S E=\frac{R M S E}{E T_{E C, \text { max }}-E T_{E C, \text { min }}}$

where $E T_{R S, i}$ is the $i$ th model-estimated ET from a remote sensing model; $E T_{E C, i}$ is the $i$ th observed ET from eddy covariance; $\overline{E T_{R S}}$ is the average of the model-estimated ET; $\overline{E T_{E C}}$ is the average of the observed $\mathrm{ET} ; E T_{E C \text {,max }}$ is the maximum of the observed $\mathrm{ET} ; E T_{E T \text {,min }}$ is the minimum of the observed ET and $n$ is the number of data.

$R^{2}$ is the regression relation between the observed ET and model-estimated ET; RMSE is the measure of agreement between the predicted and observed values whereas NRMSE is non-dimensional form of RMSE. While $R^{2}=1$ denotes a perfect correlation between the modeled and observed ET, RMSE $=0$ denotes a perfect agreement between model-estimated and field-observed ET, lower NRMSE indicates less residual variance.

\section{Results}

\subsection{Hourly ET comparison}

Fig. 3 plots a comparison of hourly ET from the eddy covariance, SEBAL model and 3T model. The plot shows that the 3T model captures daily variations in ET during the four investigated growth stages of cotton in the study area. A good agreement is noted between the measured hourly ET by eddy covariance $\left(E T_{E C h}\right)$ and

Table 2

Comparative details of relevant inputs of the SEBAL and 3T models for cotton fields in Taklamakan desert oasis.

\begin{tabular}{|c|c|c|}
\hline Inputs & SEBAL model & 3T model \\
\hline $\begin{array}{l}\text { Remote sensing } \\
\text { data }\end{array}$ & $\begin{array}{l}\text { Hyperspectral band } \\
\text { Band1 }(0.62-0.67 \mu \mathrm{m}) \text { - Band2 }(0.841-0.876 \mu \mathrm{m})-\text { Band3 }(0.459- \\
0.479 \mu \mathrm{m})- \text { Band } 4(0.545-0.565 \mu \mathrm{m})-\text { Band8 }(0.405-0.42 \mu \mathrm{m})-\text { Band9 } \\
(0.438-0.448 \mu \mathrm{m})-\text { Band10 }(0.483-0.493 \mu \mathrm{m})-\text { Band } 11(0.526- \\
0.536 \mu \mathrm{m})- \text { Band14 }(0.673-0.683 \mu \mathrm{m})-\text { Band15 }(0.743-0.753 \mu \mathrm{m})- \\
\text { Band17 }(0.89-0.92 \mu \mathrm{m}) \text { - Band19 }(0.915-0.965 \mu \mathrm{m}) \\
\text { Thermal infrared } \\
\text { Surface temperature }\end{array}$ & $\begin{array}{l}\text { Hyperspectral band } \\
\text { Band1 }(0.62-0.67 \mu \mathrm{m})-\text { Band2 }(0.841-0.876 \mu \mathrm{m})-\text { Band3 }(0.459- \\
0.479 \mu \mathrm{m})- \text { Band } 4(0.545-0.565 \mu \mathrm{m})-\text { Band8 }(0.405-0.42 \mu \mathrm{m})-\text { Band9 } \\
(0.438-0.448 \mu \mathrm{m})-\text { Band10 }(0.483-0.493 \mu \mathrm{m})-\text { Band11 }(0.526- \\
0.536 \mu \mathrm{m})- \text { Band14 }(0.673-0.683 \mu \mathrm{m})-\text { Band } 15(0.743-0.753 \mu \mathrm{m})- \\
\text { Band17 }(0.89-0.92 \mu \mathrm{m}) \text { - Band19 }(0.915-0.965 \mu \mathrm{m}) \\
\text { Thermal infrared } \\
\text { Surface temperature }\end{array}$ \\
\hline $\begin{array}{l}\text { Meteorological } \\
\text { data }\end{array}$ & Air temperature, wind speed & Air temperature \\
\hline Parameters & $\varepsilon_{0}, \varepsilon_{a}, \sigma, \alpha, N D V I, \rho_{a}, C_{p}, u_{*}, k, Z_{o m}, Z_{r e f}, Z_{0 h}, \Psi_{m}, \Psi_{h}$ & $\varepsilon_{0}, \varepsilon_{a}, \sigma, \alpha, N D V I, N D V I_{\min }, N D V I_{\max }$ \\
\hline
\end{tabular}



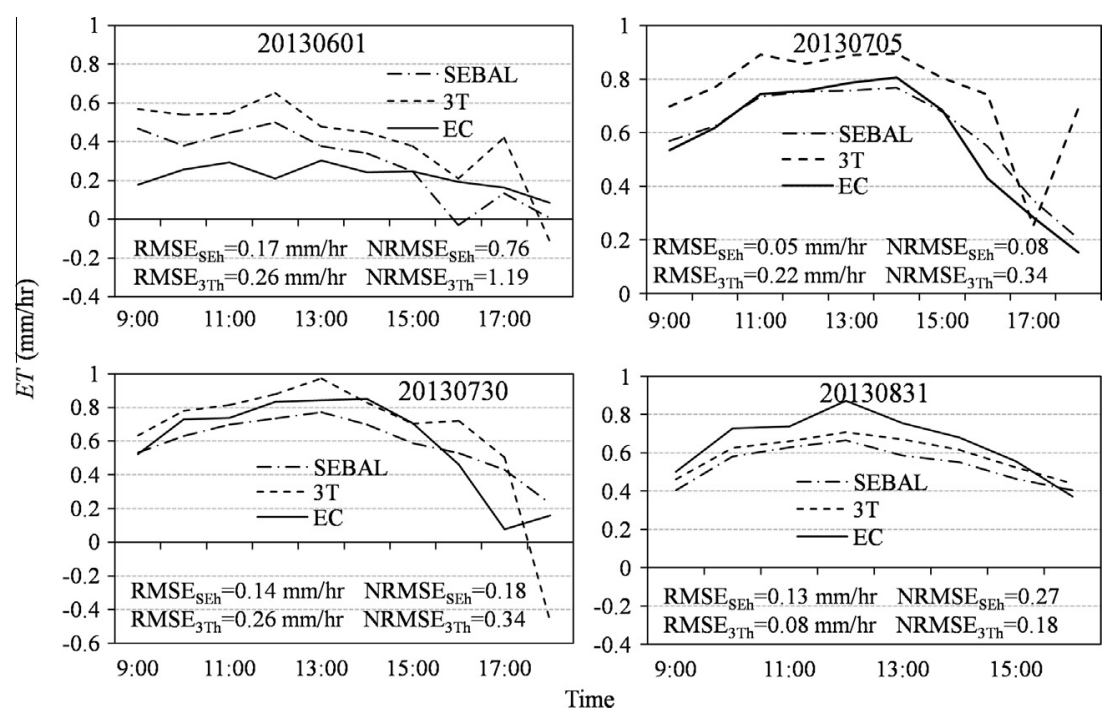

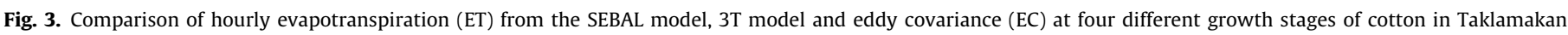

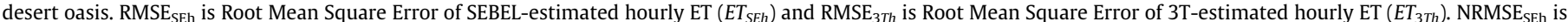
Normalized Root Mean Square Error of $E T_{S E h}$ and $\mathrm{NRMSE}_{3 T h}$ is Normalized Root Mean Square Error of $E T_{3 T h}$.

estimated hourly ET by SEBAL $\left(E T_{S E h}\right)$ and 3T $\left(E T_{3 T h}\right)$ models. The correspondence of $E T_{S E h}$ with $E T_{3 T h}$ is especially strong when variations in $E T_{E C h}$ are out of phase with variations in $E T_{S E h}$ and $E T_{3 T h}$. For instance, there is a strong correspondence between $E T_{S E h}$ and $E T_{3 T h}$ at $1200 \mathrm{~h}$ and $1600 \mathrm{~h}$ on the 1st of June 2013 (Fig. 3). Notablely, there is significant error in $E T_{3 T h}$ for the late afternoons of June 1, July 5 and July 30 and the early morning of June 1 2013, while $E T_{\text {SEh }}$ does not show similar error at the same time.

Besides, the 3T model performs differently at the different growth stages of cotton in the study area. At squaring, bolling and boll opening stages when both NDVI and ET are relatively high, $E T_{3 T h}$ agrees well with $E T_{E C h}$. However, at seedling stage when NDVI and $\mathrm{ET}$ are low, $E T_{3 T h}$ has a relatively large error, just as the case for $E T_{S E h}$.

Fig. 4 plots daily ET from the 3T model $\left(E T_{3 T d}\right)$, eddy covariance $\left(E T_{E C d}\right)$ and the SEBAL model $\left(E T_{S E d}\right)$. Absolute errors for $E T_{3 T d}$ and $E T_{S E d}$ are annotated on top of the respective bars. Note that in the daily ET plots, hourly ET $\left(E T_{3 T h}\right)$ for the early morning of June 1 and late afternoons of June 1 , July 5 and July 30 are excluded due to high instability. Compared with $E T_{E C d}, E T_{3 T d}$ is $16 \%$ higher at squaring and bolling stages, 69\% higher at seedling stage and $9 \%$ lower at boll opening stage of cotton in the study area. Also compared with $E T_{S E d}, E T_{3 T d}$ is $15 \%$ higher at squaring and bolling stages,

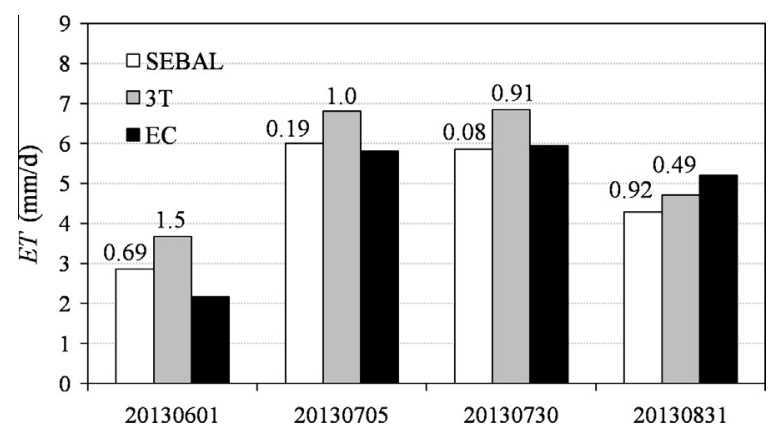

Fig. 4. Comparison of daily evapotranspiration (ET) from the $3 T$ model $\left(E T_{3 T d}\right)$, SEBAL model $\left(E T_{S E d}\right)$ and eddy covariance (EC) $\left(E T_{E C d}\right)$ for four growth stages of cotton in Taklamakan desert oasis. Note that unstable ET values for the 3T model in the early morning and late afternoons are excluded. The numbers above the bars are the absolute errors for $E T_{S E d}$ and $E T_{3 T d}$ in $\mathrm{mm} / \mathrm{d}$.
$28 \%$ higher at seedling stage and $9 \%$ higher at boll opening stage of cotton growth.

\section{2. $3 T$ model-estimated ET instability}

To explain the large error the 3T model-estimated ET for the early morning of June 1 and the late afternoons of June 1, July 5 and July 30 , the daily variations in temperature for the four days are plotted in Fig. 5. The error is largely during the period when dry soil surface temperature closely tracks air temperature, implying extremely high (positive) or low (negative) temperature index - $\left(T_{c}-T_{a}\right) /\left(T_{s d}-T_{a}\right)$. Low temperature index for the early morning of June 1 and late afternoon of July 5 results in overestimation of ET by the 3T model. Conversely, high temperature index for the late afternoon of June 1 and July 30 results in underestimation of ET by the $3 \mathrm{~T}$ model. These extreme values result in high instability in the $3 \mathrm{~T}$ model, thus the estimated ET becomes unreliable.

\subsection{Average hourly ET comparison}

Fig. 6 depicts correlation plots for the 3T model-estimated ET and eddy covariance measured ET and then for the SEBAL-estimated ET and eddy covariance measured ET (with unstable values for the early morning and late afternoon excluded). High correlation coefficients are obtained for both the remote sensing models, with $R^{2}=0.64$ for the 3T model and $R^{2}=0.73$ for the SEBAL model. Overall, the 3T model-estimated ET slightly exceeds that of eddy covariance. The line of best fit for the 3T model is somewhat parallel to that for SEBAL model and also with very similar slopes (Fig. 6).

\subsection{Effect of wind speed on ET}

The SEBAL model uses wind speed and complex physicallybased processes to compute resistance and ET. However, in 3T model, wind speed is not included in the calculation process of ET. Thus Fig. 7 compares the accuracy of the estimated ET by the two models with eddy covariance observed ET under different wind speeds. 

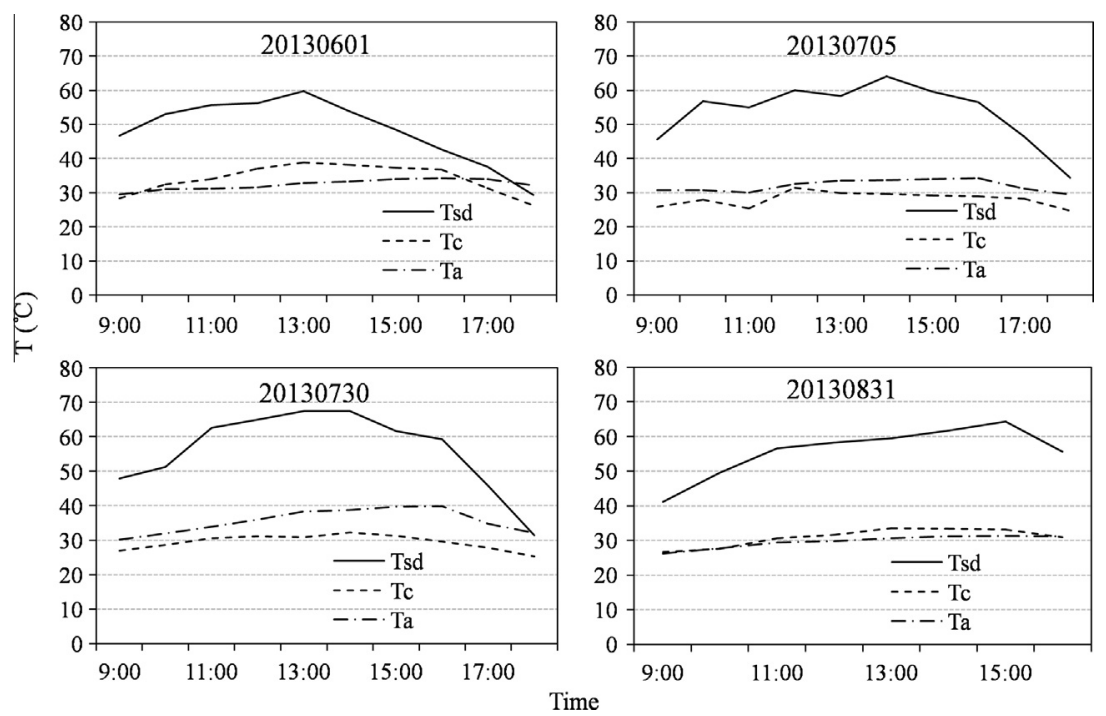

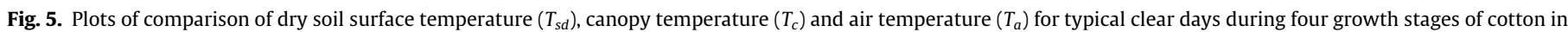
Taklamakan desert oasis.

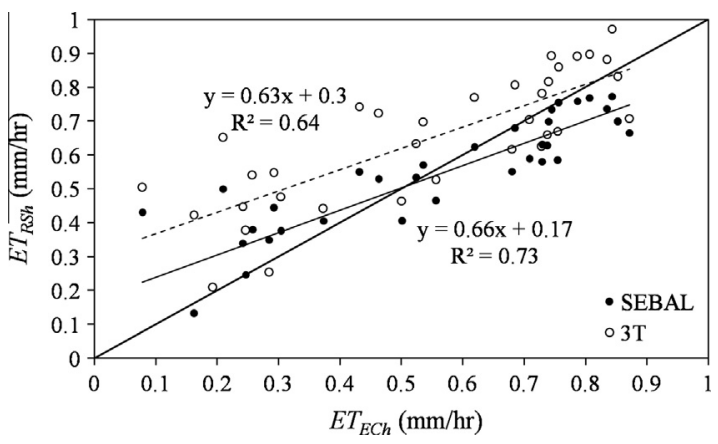

Fig. 6. Comparison of correlation between hourly evapotranspiration (ET) from the 3T model $\left(E T_{3 T h}\right)$ and eddy covariance $\left(E T_{E C h}\right)$ with that between hourly ET from the SEBAL model $\left(E T_{S E h}\right)$ and $E T_{E C h}$. Note that unstable $E T_{3 T h}$ values for early mornings and late afternoons are excluded. Also $E T_{R S h}$ is hourly ET from the remote sensing models. The dotted line is the line of best fit for the 3T model and the solid line the line of best fit for the SEBAL model.

The plot shows that differences in wind speed have no significantly effect on the estimated ET. Under wind speed of $1-2 \mathrm{~m} / \mathrm{s}$, highest $R^{2}$ value for $E T_{3 T h}$ and $E T_{E C h}(0.91)$ is observed with a perfect slope of 1 . The $R^{2}(0.65)$ and slope (0.55) are slightly lower at wind speeds $<1 \mathrm{~m} / \mathrm{s}$ and $>2 \mathrm{~m} / \mathrm{s}$. Correspondingly, SEBAL model generally performs slightly better than $3 \mathrm{~T}$ model in terms of both slope and $R^{2}$ (closer to 1 ).

Fig. 8 shows the comparison of ET by 3T model, SEBAL model and observation results from eddy covariance under different wind speed. $\mathrm{RMSE}_{3 T h}$ shows that the difference between $E T_{3 T h}$ and $E T_{E C h}$ is $0.18 \mathrm{~mm} / \mathrm{h}$. After taking out the two low $E T_{3 T h}$ values (less than $0.2 \mathrm{~mm} / \mathrm{h}$ ) with relatively large error occurring at earlier morning and late afternoon, the RMSE 3 ih drops to $0.14 \mathrm{~mm} / \mathrm{h}$, only slightly higher than $0.12 \mathrm{~mm} / \mathrm{h}$, the RMSE $\mathrm{SEh}_{\mathrm{S}}$ by SEBAL model. Besides, $E T_{3 T h}$ is always $0.1-0.2 \mathrm{~mm} / \mathrm{h}$ higher than $E T_{E C h}$, though the gaps between $E T_{3 T h}$ and $E T_{E C h}$ become smaller when wind speed is larger than $4 \mathrm{~m} / \mathrm{s}$.

\section{Discussions}

As a physical-based model, 3T model has much simpler algorithms and less demand of meteorological input than other ET models based on remote sensing technology like SEBAL model (Qiu et al., 1998). The successful application of 3T model would be helpful for ET estimation in arid region owing to the scarcity of meteorological observation stations. While 3T model and SEBAL model share the same procedures for the calculation of energy components such as net radiation and soil heat flux, procedures for sensible heat calculation, especially aerodynamic resistance, differ. While wind speed is used as the main input to calculate sensible heat in SEBAL model, three temperatures such as air temperature, canopy temperature, and dry soil temperature are extracted for sensible heat calculation in 3T model. Thus, discussions are focused on the reliability of the 3T model under the influence of daily temperature variation and wind speed.

\subsection{Applicability of $3 T$ model in daily scale}

The differences among the three temperatures (dry soil, canopy and air temperatures) are high for daytime and low for nighttime. Figs. 3 and 5 suggest that when differences among three temperatures are low, large errors occur in estimated ET by 3T model for the morning and evening periods. A similar phenomenon was also observed by Qiu et al. (1998, 2000). Thus only daytime temperatures are considered suitable for application of 3T model.

In Japan, daytime period for the 3T model is defined as 0700 $1800 \mathrm{~h}$ (Qiu et al., 1998). In the investigated desert oasis in the study, daytime duration is shortened by the rapid rise and fall in soil temperature in early morning and late afternoon, respectively. Thus, early morning and late afternoon should be avoided for 3T model application and the suggested time for $3 \mathrm{~T}$ model application in the desert oasis is 0900-1600.

\subsection{Wind speed influence on $3 T$ model}

For SEBAL model, previous sensitivity analysis showed that a $10 \%$ variation in wind speed could result in $2.0 \%$ variation in ET (Long et al., 2011; Mokhtari et al., 2013). For 3T model, the influence of wind speed on ET has not yet been reported. Our study preliminarily shows that wind speed does not influence the accuracy of ET estimation by 3T model. This is more obvious when wind speed is over $4 \mathrm{~m} / \mathrm{s}$ as in Fig. 8. It is considered that the effect of wind speed on ET has been reflected by the change of surface 


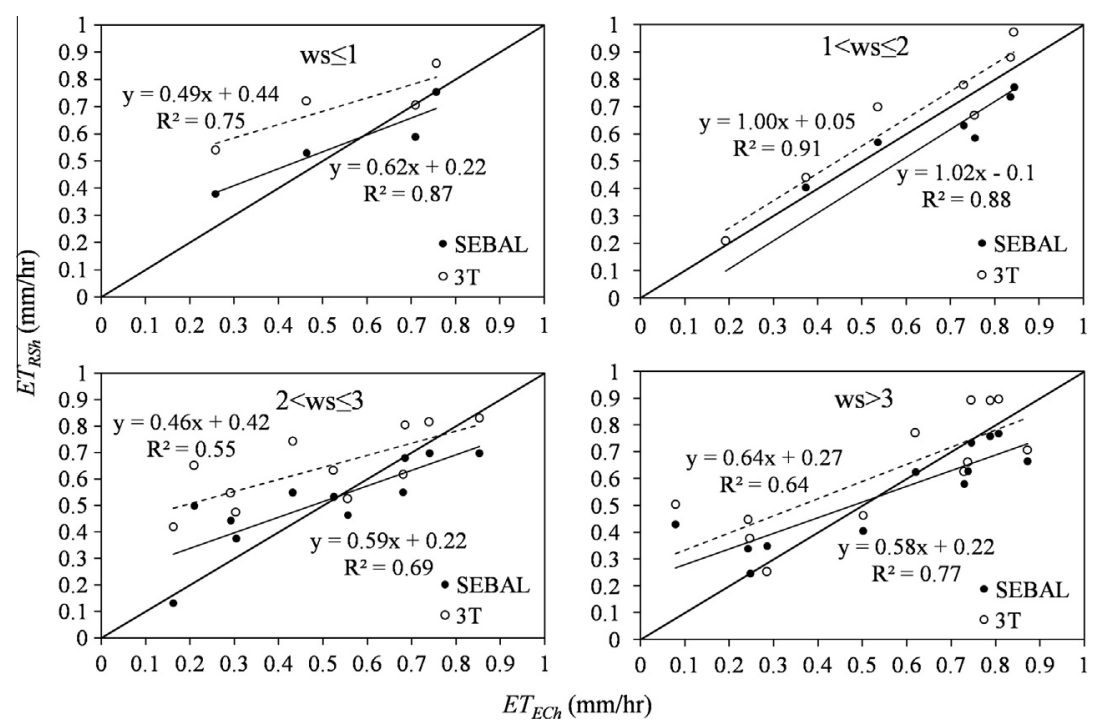

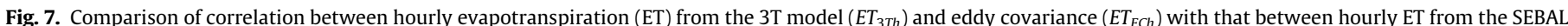

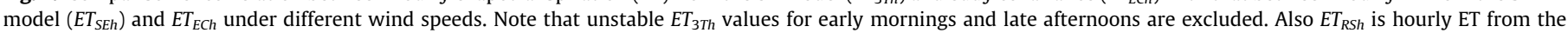
remote sensing models and ws denotes wind speed. The dotted line is the line of best fit for the 3T model and the solid line the line of best fit for the SEBAL model.

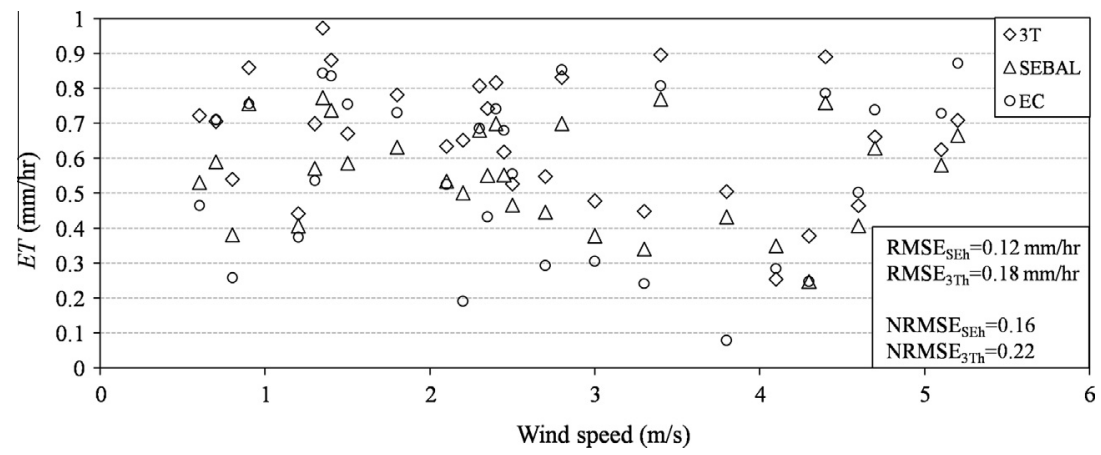

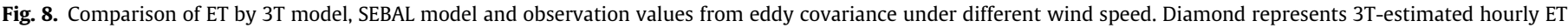
$\left(E T_{3 T h}\right)$, triangle represents SEBEL-estimated hourly ET $\left(E T_{S E h}\right)$ and circle represents observation values from eddy covariance $\left(E T_{E C h}\right)$.

temperature through its increasing influence on energy dispersion when wind speed is high. A more carefully analysis suggests that large difference between $E T_{3 T h}$ and $E T_{E C h}$ occurs at later afternoon and earlier morning, which is similar to earlier discussion.

\subsection{General reliability of the $3 T$ model}

In this study, 3T model estimated ET is averagely 23\% higher than eddy covariance observed ET for the entire cotton growth period. By contrast, the SEBAL model estimated ET is only $4 \%$ higher than ET from eddy covariance. Although the overestimation of ET by 3T model is higher than that of SEBAL model, it in no way suggests that SEBAL outperforms 3T owing to the fact that eddy covariance generally underestimates ET by $10-30 \%$ (Twine et al., 2000; Vinukollu et al., 2011).

For instance, long-term observations in two FLUXNET sites in US show that eddy covariance underestimates by $23 \%$ for maize and $28 \%$ for winter wheat (Wilson et al., 2002). It is widely observed that in China, eddy covariance averagely underestimates ET by 15\% for maize (Li et al., 2007; Guo et al., 2012), 13\% for rice (Zhu et al., 2007) and 5\% for wheat (Tong and Tian, 2009; Li et al., 2005).

Unfortunately though, there is lack of consistent ET evaluation for cotton in these regions. Considering the potential of eddy covariance to underestimate ET, the SEBAL model could have underestimated ET and the 3T model slightly overestimated ET in this study. In general, errors in the $3 \mathrm{~T}$ model are much less and therefore the estimated ET is reliable and acceptable. In addition, due to low ET partition in the energy balance, the accuracy of model-estimated ET generally falls at seedling stage (Baldocchi et al., 2000; Lee and Hu, 2002; Aubinet et al., 2000). This also holds true for both the SEBAL and $3 \mathrm{~T}$ models.

\section{Conclusions}

The results of this study could lead to several conclusions regarding the application of $3 \mathrm{~T}$ model in estimating ET. Firstly, 3T model satisfactorily captures daily and seasonal variations in ET. Secondly, 3T model has high estimation error for early morning and late afternoon hours. This is attributed to extreme positive and negative temperature indices when dry soil surface temperature approaches air temperature. This suggests that $3 \mathrm{~T}$ model is not so suitable for application in early and late hours of the day or during low temperature periods. Thirdly, the high discrepancy between the 3T model estimated ET and eddy covariance derived ET (read as 3T model error) could be due to the non-closure of energy budget by eddy covariance system. Fourthly, the accuracy of the 3T model is not significantly affected by wind speed. Overall, the 3T model proves to be a simple, yet a fairly reliable model for estimation of daytime ET at regional scale. 


\section{Acknowledgments}

We are grateful for the financial supports by the national 973 Project (2010CB951002) and the International Collaborative Project (2012DFG90290) of the Ministry of Science and Technology.

\section{References}

Allen, R.G., Morse, A., Tasumi, M., Trezza, R., Bastiaanssen, W., Wright, J.L., Kramer W., 2002. Evapotranspiration from a satellite-based surface energy balance for the Snake Plain Aquifer in Idaho. Proc. USCID Conference, USCID, Denver.

Allen, R.G., Tasumi, M., Trezza, R., 2007. Satellite-based energy balance for Mapping Evapotranspiration with Internalized Calibration (METRIC) - Model. J. Irrigation Drainage Eng. 133 (4), 380-394.

Anderson, M.C., Norman, J.M., Diak, G.R., Kustas, W.P., Mecikalski, J.R., 1997. A twosource time-integrated model for estimating surface fluxes using thermal infrared remote sensing. Remote Sens. Environ. 60 (2), 195-216.

Aubinet, M., Grelle, A., Ibrom, A., Rannik, Ü., Moncrieff, J., Foken, T., Kowalski, A.S., Martin, P.H., Berbigier, P., Bernhofer, C., Clement, R., Elbers, J., Granier, A., Grünwald, T., Morgenstern, K., Pilegaard, K., Rebmann, C., Snijders, W., Valentini, R., Vesala, T., 2000. Estimates of the annual net carbon and water exchange of forests: the EUROFLUX methodology. Adv. Ecol. Res. 30, 113-175.

Baldocchi, D.D., Law, B.E., Anthoni, P.M., 2000. On measuring and modeling energy fluxes above the floor of a homogeneous and heterogeneous conifer forest. Agric. For. Meteorol. 102 (2-3), 187-206.

Bastiaanssen, W.G.M., 2000. SEBAL-based sensible and latent heat fluxes in the irrigated Gediz Basin, Turkey. J. Hydrol. 229 (1-2), 87-100.

Bastiaanssen, W.G.M., Chandrapala, L., 2003. Water balance variability across Sri Lanka for assessing agricultural and environmental water use. Agric. Water Manag. 58 (2), 171-192.

Bastiaanssen, W.G.M., Menenti, M., Feddes, R.A., Holtslag, A.A.M., 1998a. A remote sensing surface energy balance algorithm for land (SEBAL). 1. Formulation. J. Hydrol. 212-213, 198-212.

Bastiaanssen, W.G.M., Pelgrum, H., Wang, J., Ma, Y., Moreno, J.F., Roerink, G.J., van der Wal, T., 1998b. The surface energy balance algorithm for land (SEBAL). Part 2: Validation. J. Hydrol. 212-213, 213-229.

Bastiaanssen, W.G.M., Noordman, EJ.M., Pelgrum, H., Davids, G., Thoreson, B.P., Allen, R.G., 2005. SEBAL model with remotely sensed data to improve water resources management under actual field conditions. J. Irrigation Drainage Eng. 131 (1), 85-93.

Carlson, T., 2007. An overview of the "triangle method" for estimating surface evapotranspiration and soil moisture from satellite imagery. Sensors 7, 16121629.

Carlson, T.N., Gillies, R.R., Schmugge, T.J., 1995. An interpretation of methodologies for indirect measurement of soil water content. Agric. For. Meteorol. 77 (3-4), $191-205$.

Cleugh, H.A., Leuning, R., Mu, Q., Running, S.W., 2007. Regional evaporation estimates from flux tower and MODIS satellite data. Remote Sens. Environ. 106, 285-304.

Courault, D., Seguin, B., Olioso, A., 2005. Review on estimation of evapotranspiration from remote sensing data: from empirical to numerical modeling approaches. Irrigation Drainage Syst. 19, 223-249.

Crippen, R.E., 1990. Calculating the vegetation index faster. Remote Sens. Environ. 34 (1), 71-73.

Dodds, P., Meyer, W., Barton, A., 2005. A review of methods to estimate irrigated reference crop evapotranspiration across Australia. Technical Report 04/05, CRC for irrigation futures and CSIRO land and water, Adelaide, South Australia.

Guo, J., Li, Q., Li, Y., 2012. On energy exchange of dry-land spring maize field in Loess Plateau (in Chinese). J. Beijing Univ. Agric. 27 (1), 1-5.

Hemakumara, H.M., Chandrapala, L., Moene, A.F., 2003. Evapotranspiration fluxes over mixed vegetation areas measured from large aperture scintillometer. Agric. Water Manag. 58 (2), 109-122.

Kalma, J.G., 1989. A comparison of expressions for the aerodynamic resistance to sensible heat transfer. CSIRO Div. Water Resour. Tech. Memorandum 89 (6), 11.

Kite, G.W., Droogers, P., 2000. Comparing evapotranspiration estimates from satellites, hydrological models and field data. J. Hydrol. 229, 3-18.

Lee, X., Hu, X., 2002. Forest-air fluxes of carbon, water and energy over non-flat terrain. Boundary-Layer Meteorol. 103 (2), 277-301.

Li, Z., Yu, G., Wen, X., Zhang, L., Ren, C., Fu, Y., 2005. Energy balance closure at ChinaFLUX sites. Sci. China Ser. D Earth Sci. 48, 51-62, Supp. I.

Li, W., Xu, Z., Wang, Y., Zhou, L., Zhou, G., 2007. Latent and sensible heat fluxes and energy balance in a maize agroecosystem (in Chinese). J. Plant Ecol. 31 (6), 1132-1144.

Liu, S., Mao, D., Lu, L., 2006. Measurement and estimation of the aerodynamic resistance. Hydrol. Earth Syst. Sci. Discuss. 3, 681-705.

Long, D., Singh, V.P., Li, Z.L., 2011. How sensitive is SEBAL to changes in input variables, domain size and satellite sensor? J. Geophys. Res. 16, D21107.

Luo, X., Wang, K., Jiang, H., Sun, J., Zhu, Q., 2012. Estimation of land surface evapotranspiration over the Heihe River basin based on the revised threetemperature model. Hydrol. Process. 26, 1263-1269.
Ma, L., Yang, Y., Yang, Y., Xiao, D., Bi, S., 2011. The distribution and driving factors of irrigation water requirements in the North China Plain. J. Remote Sensing 15 (2), 324-339.

Meyer, W., 1999. Standard reference evaporation calculation for inland, south eastern Australia. Technical report 35/98 Adelaide, CSIRO Land and Water, South Australia.

Mohamed, Y.A., Bastiaanssen, W.G.M., Savenije, H.H.G., 2004. Spatial variability of evaporation and moisture storage in the swamps of the upper Nile studied by remote sensing techniques. J. Hydrol. 289 (1-4), 145-164.

Moiwo, J.P., Yang, Y., Yan, N., Wu, B., 2011. Comparison of evapotranspiration estimated by ET-Watch with that derived from combined GRACE and measured precipitation data in Hai River Basin, North China. Hydrol. Sci. J. 56 (2), 249-267.

Mokhtari, M.K., Ahmad, B., Hoveidi, H., Busu, I., 2013. Sensitivity analysis of METRICbased evapotranspiration Algorithm. Int. J. Environ. Res. 7 (2), 407-422.

Norman, J.M., Kustas, W.P., Humes, K.S., 1995. Source approach for estimating soil and vegetation energy fluxes in observations of directional radiometric surface temperature. Agric. For. Meteorol. 77 (3-4), 263-293.

Qiu, G., Momii, K., Yano, T., 1996a. Estimation of plant transpiration by imitation leaf temperature, I: theoretical consideration and field verification. Trans. Jpn. Soc. Irrigation Drainage Reclamation Eng. 64 (3), 401-410.

Qiu, G., Yano, T., Momii, K., 1996b. Estimation of plant transpiration by imitation leaf temperature II application of imitation leaf temperature for detection of crop water stress. Trans. Jpn. Soc. Irrigation, Drainage Reclamation Eng. 64 (5), 767-773.

Qiu, G., Yano, T., Momii, K., 1998. An improved methodology to measure evaporation from bare soil based on comparison of surface temperature with a dry soil surface. J. Hydrol. 210 (1-4), 93-105.

Qiu, G., Ben-Asher, J., Yano, T., Momii, K., 1999. Estimation of soil evaporation using the differential temperature method. Soil Sci. Soc. Am. J. 63 (6), 1608-1614.

Qiu, G., Miyamoto, K., Sase, S., Okushima, L., 2000. Detection of crop transpiration and water stress by temperature-related approach under field and greenhouse conditions. Jpn. Agric. Res. Q. 34, 29-37.

Qiu, G., Miyamoto, K., Sase, S., Gao, Y., Shi, P., Yano, T., 2002. Comparison of the three-temperature model and conventional models for estimating transpiration. Jpn. Agric. Res. Q. 36 (2), 73-82.

Qiu, G., Sase, S., Shi, P., Ding, G., 2003. Theoretical analysis and experimental verification of a remotely measurable plant transpiration transfer coefficient. Jpn. Agric. Res. Q. 37 (3), 141-149.

Qiu, G., Shi, P., Wang, L., 2006. Theoretical analysis of a remotely measurable soi evaporation transfer coefficient. Remote Sens. Environ. 101, 390-398.

Su, Z., 2002. The surface energy balance system (SEBS) for estimation of turbulent heat fluxes. Hydrol. Earth Syst. Sc. 6 (1), 85-99.

Thoreson, B., Clark, B., Soppe, R., Keller, A., Bastiaanssen, W.G.M., Eckhardt, J., 2009 Comparison of evapotranspiration estimates from remote sensing (SEBAL), water balance, and crop coefficient approaches. World Environ. Water Resour. Congr. 2009, 4347-4361.

Tian, F., Oiu, G., Yang , Y., Lu, Y., Xiong, Y., 2013. Estimation of evapotranspiration and its partition based on an extended three-temperature model and MODIS products. J. Hydrol. 498, 210-220.

Tong, Y., Tian, H., 2009. Analysis of energy balance closure of Shouxian wheat field (in Chinese). Chinese Agric. Sci. Bull. 25 (18), 384-387.

Twine, T.E., Kustas, W.P., Norman, J.M., Cook, D.R., Houser, P.R., Meyer, T.P., Prueger, J.H., Starks, P.J., Wesely, M.L., 2000. Correcting eddy-covariance flux underestimates over a grassland. Agric. For. Meteorol. 103, 279-300.

Vinukollu, R.K., Wood, E.F., Ferguson, C.R., Fisher, J.B., 2011. Global estimates of evapotranspiration for climate studies using multi-sensor remote sensing data: evaluation of three process-based approaches. Remote Sens. Environ. 115, 801823.

Wilson, K., Glodstein, A., Galge, E., Aubinet, M., Baldocchi, D., Berbigier, P., Bernhofer C., Ceulemans, R., Dolman, H., Field, C., Grelle, A., Ibrom, A., Law, B.E., Kowalski, A., Meyers, T., Moncrieff, J., Monson, R., Oechel, W., Tenhunen, J., Valentini, R. Verma, S., 2002. Energy balance closure at FLUXNET sites. Agric. For. Meteorol. $113,223-243$.

Xiong, Y., Qiu, G., 2011. Estimation of evapotranspiration using remotely sensed land surface temperature and the revised three-temperature model. Int. J. Remote Sens. 32 (20), 5853-5874.

Yang, Y., Long, D., Shang, S., 2013. Remote estimation of terrestrial evapotranspiration without using meteorological data. Geophys. Res. Lett. 40 (12), 3026-3030.

Yu, J., Yang, G., Wang, Y., Wang, C., 2011. Research on soil moisture in Fuxin based on inversion of MODIS data (in Chinese). Remote Sensing Technol. Appl. 26 (4), 413-419.

Zhang, J., Zhang, Q., Huang, J., 2010. Application of aerodynamic resistance arithmetic in semi-arid region of China and retrieval from remote sensing (in Chinese). Plateau Meteorol. 29 (3), 662-670.

Zhang, X., Wu, J., Wu, H., Li, Y., 2011. Simplified SEBAL method for estimating vast areal evapotranspiration with MODIS data. Water Sci. Eng. 4 (1), 24-35.

Zhu, Y., Wu, J., Hu, J., Tong, C., Han, J., 2007. Energy balance closure at rice paddy fields in subtropical region (in Chinese). Chinese Agric. Sci. Bull. 23 (8), 536539.

Zwart, S.J., Bastiaanssen, W.G.M., 2004. Review of measured crop water productivity values for irrigated wheat, rice, cotton and maize. Agric. Water Manag. 69 (2), 115-133. 